\title{
Case report: a severe hypernatremia with multiple organ failure, about a clinical observation
}

\author{
Alpha Oumar BAH ${ }^{1}$, Mamadou Cellou BALDE ${ }^{2}$, Amadou BAH $^{3}$ and Alpha Oumar BARRY \\ ${ }^{1}$ Departement of Nephrology, Donka National Hospital, CHU Conakry, Guinea \\ ${ }^{2}$ Departement of Nephrology-Hemodialysis, Chiva Hospital, Foix Cedex, France \\ ${ }^{3}$ Departement of Diabetology, Donka National Hospital, CHU Conakry, Guinea \\ ${ }^{4}$ Departement of Reanimation, Donka National Hospital, CHU Conakry, Guinea
}

\begin{abstract}
A hypernatremia severe is often associated with a poor prognosis, especially if it is associated with multiple organ failure. In a country with very limited resources, the prognosis may be favorable in the absence of renal replacement.

We report the case of a 63 years old patient, hypertensive and diabetic, admitted to the ICU for unconsciousness.

Clinically, neurological examination notes a Glasgow of 8/15 (Y2, V2, M4) and a left hemiplegia. Temperature was $39^{\circ} \mathrm{C}$. Diuresis was $100 \mathrm{ml}$ during the first 24 hours. Blood pressure was $90 / 60 \mathrm{mmHg}$, tachycardia at $133 / \mathrm{min}$. Cardiac auscultation is normal. Vascular axes were weakly perceptible. Oxygen saturation was $95 \%$. The skin examination notes a dry skin and mucous membranes, a flattening of the superficial veins, sunken eyes and a persistent skin fold. There is no hepatomegaly or splenomegaly, or jaundice.

Biological point of view note natremia: 176 mmol/L; osmolarity: 390 mosmol/kg; creatinin: $300 \mu$ mol/L; glycemia > 6 g/L; transaminases 217 UI.

Diagnostics: malignant hypernatremia with a high plasma osmolarity associated with an acute anuric renal failure, hydro electrolytic disorders, an abnormal liver function, a fever of central origin and a stroke.

The treatment consisted of a correction of the electrolyte disorders by infusion of isotonic and hypotonic fluids with insulin.

Conclusion: in a country with very limited resources, the severe hypernatremia prognosis associated with anuric acute renal failure may be favorable in the absence of renal replacement.
\end{abstract}

\section{Background}

Severe hypernatremia is often associated with a poor prognosis; however, some cases of extreme hyponatremia successfully treated have been reported in the literature [1,2]. Indeed, there is a positive association between the severity of hypernatremia and mortality [3]. More generally, it is estimated that acute hypernatremia onset, greater than $160 \mathrm{mmol} / \mathrm{l}$, is associated with a mortality rate that varies between 42 and $60 \%$. This rate is lower when it is a chronic hypernatremia onset [4].

We report the case of a patient with extreme hypernatremia associated with acute anuric renal failure and multiple organ failure treated with hypo and isotonic solutions.

\section{Clinical case}

This is a 63 year old patient admitted to the emergency services of the Donka University Hospital Center for a gradual onset of coma.

His medical history is marked with type II diabetes, diagnosed ten years ago and treated with $5 \mathrm{mg}$ of glibenclamide. It is not complicated of macro and microangiopathy. She also has an old Hypertension discovered in the same year, and was treated with $10 \mathrm{mg}$ Amlodipine.

Clinically, neurological examination notes a Glasgow of 8/15 (Y2, V2, M4) and an isolated left hemiplegia. There was neither meningeal syndrome nor attacks of cranial nerves. She was febrile at $39^{\circ} \mathrm{C}$ without development of specific infectious appeal. Lumbar pits are free and painless. Diuresis was almost zero in $100 \mathrm{ml}$ during the first 24 hours. Blood pressure are rather low for a known and treated hypertensive patient. She was $90 / 60 \mathrm{mmHg}$ with no signs of shock, but tachycardia at $133 / \mathrm{min}$. Cardiac auscultation is normal without perceived cardiovascular breath. Vascular axes were weakly perceptible. It was stable on the respiratory plan with Oxygen saturation of $95 \%$ within room air without auscultatory and radiological home. The skin examination notes a dry skin and mucous membranes, a flattening of the superficial veins, sunken eyes and a persistent skin fold. There is no hepatomegaly or splenomegaly, or jaundice.

The electrocardiogram is normal, no disturbance of repolarization or conduction.

Correspondence to: Pr Alpha Oumar BAH, Chef de Service de Néphrologie, Hôpital National Donka, CHU Conakry. BP 234, Conakry, Guinea, E-mail: bahalphaoumar1@gmail.com

Key words: hypernatremia, hyperosmolar coma, multiple organ failure, acute renal failure, diabetes

Received: December 02, 2016; Accepted: December 20, 2016; Published: December 23, 2016 


\section{From a biological point of view we noted to admission}

A hypernatremia to $176 \mathrm{mmol} / \mathrm{l}$ with high plasma osmolarity to $390 \mathrm{mosmol} / \mathrm{kg}$ of water. The corrected natriemia is $186,5 \mathrm{mmol} / \mathrm{l}$. The estimated water deficit is about $10 \mathrm{~kg}$ for a typical weight of $70 \mathrm{~kg}$. There is metabolic acidosis with an alkaline reserve to $16 \mathrm{mmol} / \mathrm{l}$ and potassium levels to $5 \mathrm{mmol} / \mathrm{l}$. There was a blood volume contraction with proteins to $85 \mathrm{~g} / \mathrm{l}$ without argument for a monoclonal peak. The calcium and phosphate was correct. They were a biological inflammatory syndrome with leukocytosis $16,000 / \mathrm{mm}^{3}$ and CRP $30 \mathrm{mg} / \mathrm{l}$; the rest of the blood count notes hemoglobin to $15 \mathrm{~g} / \mathrm{dl}$ and a hematocrit to $45 \%$. The thick film (research of trophozoites of malaria) comes back positive, 0-1 trophozoite /microscopic field. Diabetes is at a high blood sugar $>6 \mathrm{~g} / \mathrm{l}$. The renal function was altered with a serum creatinine to $300 \mathrm{mmol} / \mathrm{l}$ knowing that the basis of serum creatinine was normal six months ago to $80 \mathrm{mg} / \mathrm{dL}$. Blood cultures were negative. Liver function tests noted cytolysis without cholestasis. ASAT and ALAT were to 10 times the normal, $217 \mathrm{UI} / \mathrm{l}$. The dipstick is positive for the protein and for leukocytes. It was negative for ketones and nitrites. Natriuresis on sample is less than $20 \mathrm{mmol} / \mathrm{l}$ with a ratio of $\mathrm{Na} / \mathrm{K}+$ reversed.

\section{Morphologically}

Chest X-ray is normal, no focal or radiological sign of overload, no overhang heart, heart within normal limits. The renal ultrasound shows a kidney size of $11 \mathrm{~cm}$ on each side, without dilatation of pyelocalicial cavities, the cortico-medullary index is slightly reduced; there is no lithiasis. The non-injected scaner is normal, no hematoma.

The diagnosis was a malignant hypernatremia to $176 \mathrm{mmol} / \mathrm{l}$ with a diabetic hyperosmolar coma. It is defined as a high plasma osmolarity to $390 \mathrm{mmol} / \mathrm{l}$ due to a major hyperglycemia (greater than $33 \mathrm{mmol} / \mathrm{l}$ ). Ketosis is absent. Dehydration was massive and global as evidenced by the significant weight loss of $10 \mathrm{~kg}$ and anuric acute renal failure. Fever is probably of central origin associated with hypernatremia. As to the hepatic cytolysis, it may be related to liver ischemic shock. There is no infectious sign.

The patient is first hospitalized in intensive care for a total of a week before being transferred to ensure a better monitoring and management.

Initially, she has benefited to a prudent parenteral rehydration, two liters of physiological saline solution of $0.9 \%$ during three hours to restore the hemodynamic status; then it is replaced with glucose solution of $5 \%$ associated with insulin in the absence of other hypotonic solutions. The water deficit has been corrected on $48 \mathrm{~h}$. The correction of natremia over the first twenty-four hours was $13 \mathrm{mmol} / \mathrm{l}$. Along with rehydration she received a rapid insulin treatment to correct her hyperglycemia, 6 UI per hour with a target range between 2.5 and 3 $\mathrm{g} / \mathrm{l}$. The correction of blood glucose has been slow to avoid the risk of cerebral edema.

The inflammatory syndrome normalizes with rehydration and diabetes on insulin progressively too.

Clinically, the patient gradually wakes as serum sodium is corrected.
This happens in D4 with complete disappearance of the left hemiplegia. The fever disappears within 72 hours in rehydration. The resumption of diuresis was progressive during rehydration. It started on day 1 after 10 hours of rehydration and then normalizes between D2 and D3; In the other hand, we noted the normalization of mucocutaneous signs with a weight of $67 \mathrm{~kg}$ for a typical weight of $70 \mathrm{~kg}$ (Table 1).

\section{Discussion}

A natriemia greater than $155 \mathrm{mmol} / \mathrm{l}$ at the admission is an independent mortality risk factor with an or between 2.62 and 3.64 [1]. Only a few cases of survival of patients with serum sodium greater than $170 \mathrm{mmol} / \mathrm{l}$ are described in the literature [1].

In the case of our patient, it is a malignant hypernatremia to 176 $\mathrm{mmol} / \mathrm{l}$ in association with a plasma hyperosmolarity to $390 \mathrm{mosmol} / \mathrm{l}$ in connection with a major hyperglycemia greater than $33 \mathrm{mmol} / \mathrm{l}$. Portel et al. reported a case of overall dehydration associated with a serum sodium level among the highest $(209 \mathrm{mmol} / \mathrm{l})$ and an osmolarity of $456 \mathrm{mosmol} / \mathrm{l}$ with a favorable prognosis under treatment [2]. Hyperosmolar coma is fatal in half of the cases. Prognosis depends on the time of treatment of the causal factor. It is even worse in case of vascular accident or the possible complications of decubitus installation.

A fever and diabetes mellitus are from the most common causes of hypernatremia [5]. Fever in our case would be of central origin related to hypernatremia, like cerebral hemorrhage and hemiplegia as described in the literature [6]. It is responsible in our case study, in addition to the major hyperglycemia, of an overall dehydration associated with acute renal failure anuric. The treatment consisted of a correction of electrolyte troubles by hypotonic solutions (glucose solution $2.5 \%+$ insulin) and isotonic (saline $0.9 \%$ ). In this case, the acute renal failure is functional as evidenced by the rapid improvement of renal function in rehydration associated with the correction of hyperglycemia. I recall that the natriuresis was locked (less than $20 \mathrm{mmol} / \mathrm{l}$ ) and the $\mathrm{Na}+/ \mathrm{K}+$ ratio reversed. There was not abnormal urinary sediment. All these data support the functionality character. Renal function at the output is normalized to $90 \mu \mathrm{mol} / \mathrm{l}$ of creatinin against a peak of $300 \mu \mathrm{mol}$. Water, electrolyte disorders associated with anuric acute renal failure have been successfully treated by renal replacement with hypotonic dialysate as reported by Giabicani et al. in 2015 [1] and Yang et al. in 1995 [7]. In our case, the therapeutic possibilities are very limited.

\section{Conclusion}

The severe hypernatremia prognosis associated with anuric acute renal failure may be favorable in the absence of renal replacement by a gradual correction of fluid and electrolyte disorders with hypo and isotonic solutions.

\section{Conflict of interest}

There is no conflict of interest. The script I am about to present is original and represents my work and that of my co-authors. No part of the manuscript (text, tables) has been copied or borrowed from an

Table 1. The evolution was marked by normalization of laboratory parameters.

\begin{tabular}{|c|c|c|c|c|c|}
\hline Parameters & D1 & D2 & D 3 & D 4 & D 6 \\
\hline Natremia $(\mathrm{mmol} / \mathrm{l})$ & 176 & 163 & 151 & 140 & 137 \\
\hline Creatinine $\mu \mathrm{mol} / 1$ & 300 & 200 & 179 & 127 & 110 \\
\hline Hemoglobin (g/dl) & 14,7 & 13 & 12,3 & 10,8 & 10 \\
\hline Transaminases (UI) & 217 & 170 & 141 & 131 & 10.8 \\
\hline
\end{tabular}


existing material or without a clear reference to the source.

\section{References}

1. Giabicani M, Guitard PG, Guerrot D, Grangé S, Teule L, et al. (2015) Successful treatment of extreme hypernatremia by continuous veno-venous hemodiafiltration. Nephrol Ther 11: 492-495. [Crossref]

2. Portel L, Hilbert G, Gruson D, Gbikpi-Benissan G, Cardinaud JP (1998) Survival with extreme hypernatremia at $209 \mathrm{mmol} / 1$. Intensive Care Med 24: 197-198. [Crossref]

3. Stelfox HT, Ahmed SB, Khandwala F, Zygun D, Shahpori R, et al. (2008) The epidemiology of intensive care unit-acquired hyponatraemia and hypernatraemia in medical-surgical intensive care units. Crit Care 12: R162. [Crossref]
4. Stelfox HT, Ahmed SB, Khandwala F, Zygun D, Shahpori R, et al. (2008) The epidemiology of intensive care unit-acquired hyponatraemia and hypernatraemia in medical-surgical intensive care units. Crit Care 12: R162. [Crossref]

5. Palevsky PM, Bhagrath R, Greenberg A (1996) Hypernatremia in hospitalized patients. Ann Intern Med 124: 197-203. [Crossref]

6. Snyder NA, Feigal DW, Arieff AI (1987) Hypernatremia in elderly patients. A heterogeneous, morbid, and iatrogenic entity. Ann Intern Med 107: 309-319. [Crossref]

7. Dominique J (2009) Néphrologie, Epreuves Classantes Nationales, VG.

8. Yang CW, Kim YS, Park IS, Chang YS, Yoon YS, et al. (1995) Treatment of severe acute hypernatremia and renal failure by hemodialysis. Nephron 70: 372-373. [Crossref]

Copyright: (C2016 Alpha Oumar BAH. This is an open-access article distributed under the terms of the Creative Commons Attribution License, which permits unrestricted use, distribution, and reproduction in any medium, provided the original author and source are credited. 